\title{
O ser para-si: presença transcendente
}

\section{The being-for-itself: transcendent presence}

\section{Simeão Donizeti Sass}

Doutor em Filosofia, docente do Departamento de Filosofia da Universidade Federal de Uberlândia (UFU), Uberlândia, MG - Brasil, e-mail: simeao78@gmail.com

\section{Resumo}

Nas formulações iniciais de $O$ Ser e o Nada Sartre indica que a investigação do modo como o Ser pode "ser todo" deve fazer parte do trabalho de constituição de sua ontologia. Esta preocupação é demonstrada desde o momento em que o ser do fenômeno e o cogito pré-reflexivo passam a figurar em sua reflexão. Consideramos que este problema ocupa um lugar de destaque em sua filosofia e solicita um tratamento privilegiado. Diante desta constatação, este estudo tem como intenção principal demonstrar que a análise do modo como o ser projeta a sua totalidade pode servir como fio condutor para o entendimento de alguns tópicos relevantes da ontologia de Jean-Paul Sartre.

Palavras-chave: Ontologia. Consciência. Ação. 


\section{Abstract}

Since the first steps of Being and Nothingness, Sartre has shown us that his investigation of how Being may turn into the "Whole-being" makes part of the building of his ontology. It concerns most of his thoughts as the being of the phenomenon and the pre-reflective cogito come to be the essential moments of his reflection. We consider that this problem has an outstanding position in his philosophy and therefore, it asks for a privileged treatment. By coming to this conclusion, this study has the main goal of demonstrating that the analysis of how the being projects its totality may lead us to the understanding of some relevant topics of Jean-Paul Sartre's ontology.

Keywords: Ontology. Conscience. Action.

\section{Introdução}

A análise da liberdade e, por conseguinte, da má-fé enquanto negação da angústia conduz a reflexão sartreana para o âmbito do ser da consciência. Desde a Introdução de O Ser e o Nada notamos que ela está determinada pela forma do cogito pré-reflexivo. Esse ponto de partida revela, no entanto, que o cogito funciona como princípio somente na condição de que se possa, em um momento posterior, servir de condição para que possamos transcender este fundamento. Todas as investigações acerca da realidade humana e suas condutas analisadas no ensaio de 1943 visavam a interrogar o seu ser para que fosse permitido identificar o "[...] instrumento dialético que nos permitisse encontrar no próprio cogito o meio de escaparmos da instantaneidade rumo à totalidade de ser que constitui a realidade humana" (SARTRE, 1997, p. 122). É por esse motivo que se deve interpelar, com mais vagar, a estrutura da consciência. Por intermédio dela temos a condição de apontar a correlação existente entre a discussão acerca da ontologia e a possibilidade de determinação de seu "ser todo". Para que isso seja possível, e diante do progresso realizado no campo da investigação acerca do surgimento do nada no meio do ser, investigaremos o significado da necessidade do para-si de "ser o que não é e não ser o que é".

Desde a Introdução de $O$ Ser e o Nada é possível admitir que a consciência difere radicalmente do ser em-si. Isto deve ser entendido a partir 
do fato de que, por ser intencional, ela é constituída pela determinação da não identidade. Ela não é identidade plena consigo e não representa qualquer adequação entre o que é e o que visa a ser. Ao contrário do em-si, ela é "descompressão de ser", carecendo de coincidência consigo. Considerando-se a análise da má-fé, não é difícil demonstrar que este projeto é crença "perturbada", uma fé "pela metade".

Em suma, se quisermos circunscrever o ponto de chegada do processo de determinação de si que a consciência empreende, devemos admitir que há uma correlação no seio da unidade, um reflexo (reflet) que é a sua própria reflexão (réflection). Para esclarecer essa forma de ser que é a consciência, precisamos entender e admitir, primeiramente, que a sua dimensão pré-reflexiva deve ser dada enquanto consciência (de) si, ou seja, consciência não tética. Se assim é, cabe investigar o modo pelo qual a consciência pode ser o seu si. Somente após esse esclarecimento teremos condições de entender o sentido pleno que pode ter a forma da consciência tética.

\section{O ser-para-si}

Para investigar o significado do si que a consciência projeta ser, Sartre inicia sua argumentação fazendo uma ressalva ao sentido próprio do ser que é identidade consigo, o em-si. Na verdade, o si presente na referida definição é usado indevidamente porque, em sua natureza, ele já é obtido por uma operação de reflexão, ele "um refletido". O si pressupõe uma remissão a... e o ser chamado em-si jamais pode conter tal qualidade, pois é somente uma compressão de ser. O termo si aponta para uma relação, indicando que dois momentos surgem um para o outro. Se admitimos tal posição, o em-si somente pode ser compreendido como uma identidade. O sentido do si, por outro lado, existe para designar o ser de um sujeito, apontando a relação deste sujeito consigo. Mas a dificuldade que surge está no fato de que, para Sartre, o si não aponta nem o ser do sujeito nem o do predicado. Ele não pode ser identidade consigo enquanto designa um sujeito porque este seria tomado na forma do em-si. Ele não pode ser si porque esse tipo de coincidência faria com que a própria condição de sujeito fosse invadida pelo em-si. Como consequência, temos: na verdade, o si não pode ser tomado como um existente real. Com essa conclusão Sartre quer demonstrar que o ser da consciência não pode ser reduzido ao sinal típico da reflexividade. Quando ele pensa o termo si, ele está cogitando acerca do momento no qual a consciência será unidade, a totalidade 
reflexo-refletente, unidade entre a consciência não-tética e a consciência tética. Esta unidade indivisível, na verdade, seria denominada em-si. Por outro lado, o si não pode deixar de ser si, pois ele é a designação do sujeito. Este duplo significado do termo si nos coloca, portanto, diante do dilema de determinar em que sentido uma consciência pode ser a realização de seu projeto de atingir completamente a consciência tética.

Diante dessa dupla determinação, a de ser necessário e exigido pela consciência, mas não um existente real (não identificado imediatamente pela consciência, mas constituído por um processo de determinação gradativa), é necessário admitir que o si aparece como

[...] uma distância ideal na imanência entre o sujeito e si mesmo, uma maneira de não ser sua própria coincidência, de escapar à identidade colocando-a como unidade; em suma, um modo de ser em equilíbrio perpetuamente instável entre a identidade enquanto coesão absoluta, sem traço de diversidade, e a unidade enquanto síntese de uma multiplicidade (SARTRE, 1997, p. 125).

Com essa definição vemos aparecer não mais o si como identidade prévia, mas sendo presença a si buscada pela consciência. É por isso que o modo como a consciência é consciência (de) si não mais repete a fórmula da identidade plena do ser. Ela aponta, ao contrário, para a necessidade de definirmos o modo como esta carência de identidade pode ser pensada como "unidade dos contrários". Abordar o significado do si, portanto, é adentrar no problema da totalidade. Com isto, notamos claramente que a discussão sartreana acerca do ser da consciência não pode estar situada separadamente do problema da totalidade que este ser envolve. Investiguemos um pouco melhor o modo como esta questão aparece no interior de O Ser e o Nada.

A partir do momento em que a consciência foi determinada segundo a fórmula da "presença a si" passou a ser tomada como um ser que é a própria volta para si. É por essa razão que Sartre pode estabelecer que "a lei de ser do Para-si, como fundamento ontológico da consciência, consiste em ser si mesmo sob a forma de presença a si” (SARTRE, 1997, p. 125). Esta definição da consciência que, de fato, traz uma nova significação ao termo tem a vantagem de não tomá-la como uma plenitude, tal qual vemos no em-si. A consciência perde sua aparência substancialista. Mas essa vantagem aponta para uma outra dimensão do ser que é a presença e isso revela uma diferenciação radical. Ser presença a si é estabelecer uma relação consigo. No em-si não há relação 
nem distância pelo simples fato de que a negação jamais habita seu interior. O princípio da identidade elimina qualquer tipo de relação no âmago do ser. A presença a si, ao contrário, pressupõe que uma fissura possa habitar o seu ser. Esta relação estreita entre fissura e presença é importante para a compreensão do ser para-si. Isso aponta para o surgimento de outra consequência importante: se a presença pode ser verificada é porque o ser que a experimenta não é inteiramente si mesmo.

Esta determinação põe em evidência uma nova dimensão do ser da consciência, ela pressupõe que algo possa separar o sujeito de si. Que pode haver $n a$ consciência existindo como algo que a separa de si? A resposta dada por Sartre é "desconcertante": se o sujeito é presença a si, nada o diferencia de si, ou seja, se ele se dá como constante processo de "tomada de consciência de si", nada o separa de si, a não ser a "distância" que deve ser superada.

Porém, se tomamos essa consciência posicional enquanto rompimento da relação com o seu objeto e, por isso, introduzimos a diferença no interior da imanência, recolocamos nela uma certa opacidade. Diante desse erro quase inevitável, somos obrigados a relembrar que o modo como a consciência é relação com seu objeto sempre se dá como jogo de remissão ao outro termo do ser. Se tentamos descobrir o que realmente separa a consciência (de) crença da crença notamos que a distância desaparece e ficamos somente com a imanência da crença. Se, contudo, tentamos captar a crença isolada de seu outro, da consciência, encontramos somente a sua remissão ao que não é, encontramos novamente a fissura que desejávamos evitar, "essa fissura é o negativo puro" (SARTRE, 1997, p. 126). A ausência de ser que encontramos nessa fissura somente é vislumbrada na medida em que não a focalizamos diretamente, o que relembra o "equilíbrio instável" mencionado na definição de presença a si. Esse negativo, que nada tem de próprio, mas somente expressa um poder nadificador, é o próprio Nada. Neste quadro, a crença, por exemplo, só existe como presença a si enquanto é pura descompressão de ser. Se fosse identidade consigo recairia na plenitude das coisas. Diante dessas considerações, para que a consciência seja tomada em sua propriedade, ela deve postarse ao modo do ser para-si, sendo o nada da identidade consigo. Para Sartre,

o ser da consciência, enquanto consciência, consiste em existir a distância de si como presença a si, e essa distância nula que o ser traz em seu ser é o Nada. Logo, para que exista um si, é preciso que a unidade deste ser comporte seu próprio nada como nadificação do idêntico (SARTRE, 1997, p. 127). 
Com a determinação da consciência enquanto presença a si, notamos que a sua condição é a de ser algo que determina a si mesmo a existir sem jamais poder atingir a sua identidade. Com o para-si revelado, percebemos que a consciência está, a todo tempo, projetando-se para um além de si e, na verdade, sendo reenvio de si a si, do reflexo (reflet) ao refletente (reflétant), e deste ao reflexo. Mas essa remissão se dá na unidade de um mesmo ato, ela é esse jogo que não cessa, mas como unidade do jogo dos opostos. Com o para-si, que identifica o modo de ser da consciência enquanto presença a si, surge o nada colocado pelo ser como questão para o ser. Com a presença a si, notamos que o nada vem ao ser pela realidade humana que é dado agora como aquele que "[...] é o ser, enquanto, no seu ser e por seu ser, é fundamento único do nada no coração do ser" (SARTRE, 1997, p. 128).

Se esta condição do para-si revela para a consciência a sua incapacidade de ser plena e também o seu caráter "fugidio", todavia, de alguma forma, o para-si é, mesmo que seja ao modo negativo de ser o que não é e de não ser o que é. Se o projeto de sinceridade é posto como possível, isso se dá porque ele é o lançar-se no mundo, ao mesmo tempo em que se vê abandonado em uma situação determinada. Estar abandonado no mundo, sem ter qualquer fundamento que sustente o seu ser, torna a consciência um ser que coloca a si o problema de sua origem, em outros termos, a falta de fundamento transforma a sua existência em um problema para si. Existir sem fundamento significa ser para si a interpelação do sentido acerca deste existir. A dúvida que surge, a partir do momento em que vemos o para-si como ser situado, é o modo como ele pode ser presença ao mundo. Sendo presença a si ele é para-si. Sendo presença ao mundo, que pode significar essa condição de estar situado? Como a consciência pode ser presença ao mundo?

Abordar o modo como a consciência está imersa, situada no mundo, significa pôr em discussão a "facticidade do para-si". Dizer que a consciência está em situação, que ela é fática, equivale a tomar o seu ser como puramente determinado por sua presença. Isto representa não dar a ela nenhuma outra determinação ou origem senão a de estar presente em um lugar. Isto retira de seu ser qualquer anterioridade de origem, solapando qualquer causa originária. Estar determinado pela facticidade significa ser atingido pela questão: "por que o seu ser é desta forma e não de outra?". Admitir a facticidade é "debilitar" o fundamento. Nesse sentido, dizer que algum ser é "presença ao mundo" significa isolá-lo de sua origem. Todo ser que é afetado pela dúvida acerca de sua origem é também denominado por Sartre de contingente. Notamos aqui que a busca pelo si leva ao pressuposto de que o ser carece de fundamento. 
A partir do momento em que a consciência é posta como um ser para-si, a determinação da presença a... corrói o fundamento inerente ao seu ser. Se, como diz Sartre, encontramos um "desnível” no ser, se o seu si não está em si, mas sempre distante de si, o fundamento surge como problema e não como dado originalmente. Sartre entende de forma semelhante que um ser é contingente quando ele é "injustificável". Postas estas premissas, podemos responder ao questionamento acerca do modo como a consciência, enquanto para-si, é presença ao mundo:

[...] o Para-si acha-se sustentado por uma perpétua contingência, que ele retoma por sua conta e assimila sem poder suprimi-la jamais. Esta contingência perpetuamente evanescente do Em-si que infesta o Para-si e o une ao ser-Em-si, sem se deixar captar jamais, é o que chamaremos de facticidade do Para-si (SARTRE, 1997, p. 132).

Com a identificação da facticidade do para-si reconhecemos que não é possível, para a consciência, existir sem ser o jogo com o seu sentido, sempre afirmando sua existência, mas ao modo de negar seu ser pleno. Só sou consciência se não sou o ser monolítico da identidade. Esse ser em-si escapa ao modo de existir da consciência. Ao reconhecer sua facticidade, contudo, a consciência deve admitir que uma característica estranha ao seu querer a modifica de forma inegável. Sem a facticidade, a consciência poderia escolher, indistintamente, qualquer vinculação com mundo, fundamentando, por exemplo, o modo como ela seria existência, justificando completamente o seu surgimento. A facticidade, entretanto, retira a completa determinação de si por si que a consciência desejava. Ela surge para a consciência como fato a ser negado. Uma determinação que não é desejada, mas que nunca pode ser ignorada. A facticidade funciona como uma indicação que a consciência dá para si do ser que ela deve alcançar, não o ser dado, mas uma primeira determinação que é incondicionada e que se mostra como ponto de partida para todas as demais determinações. Essa facticidade do para-si é, em certo sentido, o reconhecimento de sua absoluta contingência na tentativa de fundar-se.

Afirmávamos anteriormente, ao retomar a argumentação de Sartre, que o cogito funcionava como princípio desde que fosse possível ultrapassar a sua determinação básica. Este ponto de partida é mantido porque somente por meio dele temos condições de realizar o estudo da realidade humana. Admitir que o cogito é o modo de iniciar esta reflexão, contudo, representa tomá-lo na sua instantaneidade. Será que esta característica é suficiente para descrevermos 
o ser da realidade humana? Se assim fosse, esta realidade só encontraria a verdade do instante, um instante que necessitaria ser reposto incessantemente, imposição esta que Sartre não pode admitir. Para superar este condicionante devemos demonstrar agora que aquilo que necessita ser ultrapassado é exatamente a instantaneidade. Esta exigência levanta a seguinte interpelação acerca do cogito: "podemos ampliá-lo sem perder os benefícios da evidência reflexiva?” (SARTRE, 1997, p. 135). Retomemos o problema da nadificação.

É preciso tomar o para-si como falta de ser para que ele mantenha a nadificação. Esta falta é identificada em seu ser, não só como vazio, mas também como atitude de negação em relação a si e em relação ao em-si. Isto significa que essa falta deve ser determinada, ela solicita ser compreendida como falta de algo. Mais adiante veremos como esta determinação representa um aspecto importante do tema que tratamos. Como sabemos, o para-si suporta o nada em seu ser. Identificar a presença do em-si em sua completa aparição e na sua absoluta impossibilidade de ser atingido é uma tarefa que cabe ao cogito. Mais do que isso, esta presença do em-si é o horizonte para o qual o para-si deve transcender. O que caracteriza o pensamento de Sartre, no entanto, é a demonstração de que a transcendência, enquanto vínculo entre os dois modos de ser, só pode ser dada por meio da nadificação. É esta determinação da nadificação que aparece a Sartre como "[...] um meio de sair do cogito" (SARTRE, 1997, p. 135). Esta nova característica atribuída ao cogito, a de ser a própria transcendência, surge como a sua determinação essencial.

Feita a indicação do modo como o cogito pode ser tomado enquanto transcendência, devemos recolocar o problema da nadificação. E ele reaparece como a forma do para-si de revelar que o seu fundamento está dado como uma "falta de ser" (défaut d'être). O que é exigido agora é a determinação ou a explicitação do modo como este modo de ser do para-si torna-se possível.

Dentre vários tipos de negação, Sartre deseja explorar aquela que estabelece um vínculo interno entre o ser que nega e aquilo que é negado, o qual denomina de negação interna e que é encontrada, de forma explícita, na falta. Esta forma de negação interna é importante para a argumentação porque ela só aparece por intermédio da realidade humana. Para que ela ocorra, no entanto, devemos identificar uma trindade: 1) o faltante (manquant); 2) aquilo ao qual falta o que falta, chamado de existente (existant); e 3) uma totalidade que foi desagregada pela falta e que seria restaurada pela síntese entre o faltante e o existente, denominada faltado (manqué).

Se a realidade humana, como vimos, é falta de fundamento e origem de toda negação, por ter o nada encravado em seu ser, podemos notar que ele 
se encaixa na condição de existente. Mas se tomamos a realidade humana como exemplo, o faltante também é essa mesma existência, pois é determinada em seu ser pela totalidade sintética do faltante e por aquilo que "tem de ser". Começamos a ver aqui que o problema da totalidade surge de modo explícito. "No mundo humano, o ser incompleto que se dá à intuição como faltante é constituído em seu ser pelo faltado" (SARTRE, 1997, p. 136-137). Nesse jogo de determinação e falta, a realidade humana como existente é sua própria falta como ser. E essa dimensão aponta para o fato de que o faltante é o que a realidade humana não possui mas que precisa conquistar. Sendo assim, essa realidade humana é transcendência rumo ao ser faltado (manqué), pois almeja a síntese entre o que é e o que necessita ter para preencher a falta que a habita. A realidade humana é, dessa forma, desejo de suprimir a falta de ser que a define. Desejo que é transcendência e fuga de si rumo ao ser desejado. O desejo surge, então, como falta de ser. Vemos, por isso, que a negação interna no ser do homem o leva a tentar suprir a lacuna que o caracteriza. Porém, se essa trindade o habita, o "[...] existente é o que se dá ao cogito como o imediato do desejo" (SARTRE, 1997, p. 138). Se esse esquematismo se aplica integralmente, surge a dúvida: que é a síntese entre o faltante e o existente? Em outras palavras, como podemos definir o faltado?

Para explicitar essa questão, Sartre considera que o vínculo entre os dois primeiros termos deve ser posto de modo claro. Esse vínculo não é uma simples relação de contiguidade, um simples estar ao lado, uma relação externa. Sendo a falta uma negação que é estabelecida pelos laços de ser entre os opostos, ela só ocorre quando um nada surge sobre um fundo prévio de totalidade. O importante é que o faltante e o existente sejam dados ou captados como algo a ser negado na unidade da totalidade de que se tem falta. Tendo toda falta a determinação da carência de algo para ser preenchido e, por outro lado, sendo este algo o faltante dado na unidade de um surgimento primitivo de ser e, sendo, por outro lado, o para, na sua forma essencial, concebido como o não ainda ou o não mais, toda falta é uma ausência rumo à qual o existente precisa transcender.

Se a falta é, desse modo, o para que todo existente busca transcender, surge a questão: qual é o para que a realidade humana projeta quando transcende seu ser? Se ela é seu próprio nada como ser, somente pode visar ao seu si como supressão de seu nada. Desse modo, a realidade humana projeta ser precisamente o seu si. Na verdade, "[...] o sentido da realidade humana se constitui pelo si-como-ser-Em-si faltado" (SARTRE, 1997, p. 139), é, portanto, o si concebido como o ser completo que permite o para-si captar-se 
enquanto não é o que é. Esse projeto de conquista de si pela consciência postula uma forma de identidade, mas que existe somente como a relação perpetuamente ausente entre o para-si e o si. Em suma, o para-si carece do si mesmo enquanto identidade.

Desta forma, notamos uma diferença no modo como cada um pode ser plenitude, o em-si, na condição de ser fático, é presença ao mundo, o para-si, enquanto em-si de que se tem falta, é pura ausência que deve ser preenchida. Nesta diferenciação, podemos identificar que o projeto de síntese é sempre um fracasso anunciado, pois o para-si somente pode ser si enquanto é nada de pleno. Contudo, ele apenas reserva uma parcela de ser se consegue apreender a si não mais como plenitude mas como fracasso. A realidade humana é, por isso, captação de si enquanto é sua própria falta, reconhecendo-se como incompleta.

Mas, sendo a realidade humana transcendência rumo ao ser, este só se dá como totalidade. A totalidade para a qual ela ruma, entretanto, não é o simples em-si, ela surge, ao contrário, como o horizonte em vista do qual a conquista do seu si deve caminhar. Nisso reside o fracasso, conquistar um em-si que existe como relação sempre remissiva de polos opostos. Vemos, desse modo, que "[...] a realidade humana surge como tal em presença de sua própria totalidade ou si enquanto falta desta totalidade. E esta totalidade não pode ser dada por natureza, pois reúne em si os caracteres incompatíveis do Em-si e do Para-si" (SARTRE, 1997, p. 141).

\section{O valor}

A realidade humana busca, incessantemente, conquistar a unidade de seu ser, que Sartre denomina soi, porém, como sabemos, este não é um existente real e não pode ser atingido. Identificamos, assim, que a realidade humana é o projeto de atingir a unificação de seu ser e, nesse sentido, ver-se habitada por um ideal de totalidade.

Por outro lado, esse todo funciona como horizonte, pois se dá no mundo como ser que tende a receber toda negação. Vemos surgir desta forma a dimensão continuamente fracassada da realidade humana, como sendo a configuração da consciência infeliz, que tenta a todo o momento superar tal estado, sem jamais conseguir. Esse fracasso se dá porque a díade formada pela consciência e pelo ser jamais atinge uma unidade ou uma síntese, ou seja, uma totalidade "estável". 
Quando perguntamos para qual ser a consciência infeliz ruma, encontramos a resposta no seu soi como ser. Essa dimensão, para Sartre, tem um significado específico, isto é, tem a característica de uma estrutura fundamental do para-si que é o valor. Por intermédio dele encontramos uma dupla condição coexistindo em um ser: um incondicionado que não é. Se ele é algo, o é como valor, ou seja, uma "irrealidade" que deve ser atingida e, só então, realizada. Nele identificamos a mesma característica que tem o para-si: "é e não é o que é". Se o tomamos como uma coisa ou um fato específico, deixamos de compreendê-lo. Em outros termos, ele deve ser dado como aquilo que jamais é determinado de modo definitivo. "O valor está para além do ser" (SARTRE, 1997, p. 144). Se ele está fora de qualquer determinação específica, é, contudo, tornado possível pela realidade humana, que o assume como o si que projeta atingir. Realidade humana e valor, por esta razão, coexistem na mesma condição de ser o que não é e de não ser o que é.

Se retomarmos a trindade da falta, notaremos que o valor é o próprio faltado porque ele se dá como síntese que deveria emergir da relação entre a realidade humana e o seu si projetado. O valor é o em-si ausente que todo para-si persegue sem, contudo, poder atingir. Mas ele é esse todo nunca realizado. O valor, por ter surgido com a realidade humana, habita o seu ser enquanto funda-se, habitando a própria liberdade como valor supremo, uma vez que, existe sem ser totalmente determinado. Desse modo, a relação estabelecida com o para-si é de ordem muito particular, na qual este se dá como tendo de ser o fundamento de seu nada de ser. A síntese desta formulação pode ser encontrada na seguinte expressão: "há uma total contingência do ser-para-o-valor, que recairá imediatamente sobre toda moral para trespassála e torná-la relativa - e, ao mesmo tempo, uma livre e absoluta necessidade" (SARTRE, 1997, p. 145).

Para explicitar esta última consideração, faremos uma pequena pausa em nossa análise da estrutura da argumentação em curso para destacarmos um comentário que foi feito por Sartre quando ficou evidenciado que o valor possui a dupla característica da necessidade e da contingência. O comentário que Sartre formula da frase que citamos pode passar desapercebido para alguns por estar restrito a uma nota de rodapé, por ele elaborada, logo após o término do enunciado que mencionamos. Não podemos, contudo, desprezar tais considerações porque ali encontramos elementos importantes para a tarefa que empreendemos em nossa investigação; vejamos o seu conteúdo.

Sartre afirma que alguns analistas de sua teoria poderiam interpretar, por um erro de avaliação, que a estrutura triádica da falta, quando pensada em 
termos de valor, congregaria a seguinte forma: o em-si seria a tese, o para-si a antítese e o em-si-para-si o Valor ou a síntese. Essa estrutura aparentemente hegeliana desviaria a atenção da real importância e peculiaridade da tríade que o valor congregaria. Sartre entende que a diferença de postura de sua teoria em relação ao hegelianismo estaria na forma pela qual o para-si e o em-si poderiam ser relacionados. Segundo ele, o para-si carece da plenitude do emsi e nesse sentido conserva uma dependência real, ele sente a falta do em-si. Quando se considera o em-si, entretanto, a sua essência revela que não ocorre qualquer tipo de dependência ou de falta em relação ao para-si, ele não necessita de nada para ser, além de si próprio. Não há, por causa dessa característica do em-si, a "reciprocidade na oposição". Por possuir a estrutura da facticidade, o para-si permanece contingente em relação ao em-si. Por outro lado, a suposta síntese projetada, ou no caso, o Valor, não é a totalidade conquistada pela ultrapassagem da negação identificada nos dois primeiros elementos, ele é, na verdade, “[...] um retorno à tese, e, portanto, um retorno a si”" (SARTRE, 1997, p. 146). Mas isso também não pode ser interpretado como a solução do dilema, pois o Valor é "totalidade irrealizável" (SARTRE, 1997, p. 146), visto que o para-si não é "[...] um momento que possa ser transcendido" (SARTRE, 1997, p. 146) em direção a qualquer outro ser. Em vez de espelhar-se em uma formulação de tipo hegeliana, Sartre indica que a natureza dessa síntese está muito mais próxima das "realidades 'ambíguas' de Kierkegaard" (SARTRE, 1997, p. 146). Isto porque não se postula uma totalidade acabada; busca-se acentuar "um jogo duplo de oposições unilaterais" (SARTRE, 1997, p. 146). Aquele mesmo jogo que encontramos no momento em que se identificou a tentativa da consciência de ser e não ser a identidade do em-si, o jogo que a realidade humana faz com o ser do valor.

Neste comentário sartreano da estrutura triádica encontramos um indispensável ponto de reflexão acerca das influências que ele recebeu para apresentar a sua posição acerca do problema da totalidade e vemos aí a figura de Kierkegaard aparecendo em destaque, mesmo tendo sido pouco citado no decorrer de suas considerações. É esta compreensão que será mantida nos diversos momentos de sua reflexão. A partir deste momento veremos que a reflexão ontológica será trespassada pela possibilidade de uma totalidade vir a habitar o ser.

Esta era a pausa que desejávamos fazer para ressaltar o momento em que, pela primeira vez em $O$ Ser e o Nada, identificamos uma justificativa para a crítica de uma concepção de totalidade que postula uma síntese última dos momentos de uma contradição. Voltemos ao trabalho de análise da argumentação sartreana em torno das estruturas do para-si. 
Com o valor podemos considerar que o para-si projeta ser o seu si como totalidade, mas se identifico essa diferença entre o que sou e o que quero ser, devo admitir que o para-si é o ser que se reconhece como faltante ao modo de "ter de ser" o que ele não é. Notamos aí a busca pela identidade entre o faltante e o existente. A descrição deste processo de conquista de si, contudo, não fica completa se não indicamos que aquilo que falta a cada para-si, somente a ele, é o que Sartre define como o possível. Por ter surgido sobre um fundo de negação que é o próprio para-si a ser transcendido, ele não pode ser dado previamente, sendo, contudo, um dos aspectos de descompressão de ser que o para-si opera. O possível surge, por isso, como um modo de ser o que se é estando a uma certa distância de si. O para-si passa a ser habitado pelo valor e como projeção de seus possíveis que lhes são próprios.

Por esta razão, notamos que o cogito pode ser tomado como uma transcendência, pois é dado sob o modo de negação de si. Com ele vemos que a consciência pode ser o que não é, projetando sua própria transcendência enquanto negação interna. Compreendendo a estrutura do para-si enquanto possibilidade, temos clareza de que a partir do momento em que eu tomo ciência de meu ser imediato sou simplesmente aquilo que não sou. Desse modo, vejo-me alçado para uma dimensão nova, rumo a um sentido que está fora de alcance, mas que não pode ser confundido com uma representação subjetiva imanente. Por essa determinação, a apreensão de si da realidade humana jamais coincide com uma representação fechada e acabada de seu próprio ser, faltam coincidência e plena positividade. O possível é o para-si que falta ao para-si, mas a coincidência do si é vedada a este ser.

A partir dessas considerações, temos elementos suficientes para considerar a consciência como um incessante processo de totalização e, de modo específico, ato de negação da totalidade prévia que é o mundo. Até este momento da análise sartreana, a noção de mundo não apareceu de modo significativo e por isso não a tomamos como objeto no percurso que escolhemos. Ao adotarmos a estratégia de resgatar os momentos principais da argumentação sartreana não fomos postos diante desta tarefa. Mas agora podemos fazê-lo. É somente com a abordagem do significado daquilo que é denominado de "circuito de ipseidade" que a noção de mundo é tratada de forma específica, o que se explica pelo fato de que ele surge como o meio no qual o para-si encontra-se situado e para o qual ele deve dirigir as suas negações.

Após termos grifado que uma das determinações essenciais do para-si é a de ser negação, cabe-nos agora indicar como se dá a compreensão sartreana em relação ao destino destas negações. Devemos abordar, mesmo que seja 
de maneira indicativa, a forma como é apresentada a concepção sartreana de mundo. Isto exige que ela esteja situada como correlato necessário do "circuito de ipseidade". Em poucas palavras, podemos dizer acerca deste "circuito" que, ao indicar o modo como o para-si persegue a identidade plena consigo e admitindo que existe uma distância entre ele mesmo e a identidade que ele busca, a reflexão sartreana revelou que a "ipseidade" é determinada pela distância intransponível. Isto significa que o para-si é identidade consigo "lá longe" (SARTRE, 1997, 156). Esse "distanciamento na imanência" é o próprio "circuito de ipseidade", uma "[...] livre necessidade de ser longe do que é em forma de falta" (SARTRE, 1997, p. 156). ${ }^{1}$ Apresentado o modo como é definida a ipseidade, a noção de mundo surge como o contraponto desta definição, pois ele é "[...] a totalidade dos seres enquanto existem no interior do circuito da ipseidade" (SARTRE, 1997, p. 156).

O mundo surge, então, como "lugar" no qual a consciência pode ser a sua transcendência rumo a um momento de identidade consigo. "O que busco frente ao mundo é a coincidência com um Para-si que sou e que é consciência do mundo" (SARTRE, 1997, p. 157). Podemos notar que surge diante do para-si uma "totalidade dos seres" enquanto lugar no qual ele está situado, mas que também é o meio contra o qual ele vai exercer suas negações. Podese afirmar que o para-si aceita envolver-se nesta totalidade tomando-a como conjunto de seres que tem de dominar. Esta totalidade aparece como minha porque é contra ela que dirijo minhas atitudes. Podemos dizer que ocorre uma relação de posse porque "[...] o mundo é meu por natureza, na medida em que é correlato Em-si do nada, ou seja, do obstáculo necessário para além do qual me reencontro como aquilo que sou sob a forma de "ter-de-sê-lo"' (SARTRE, 1997, p. 157).

Se o mundo aparece como uma totalidade, ele é, ao mesmo tempo, o polo de positividade contra o qual o para-si direcionará a sua atividade negadora. Neste sentido, ele está no mundo e participa de uma totalidade, mas quando faz uso deste mundo para realizar as suas possibilidades necessita considerá-lo como meio que deve ser transcendido em vista da posse definitiva de seu ser. Vemos ressurgir então a distância entre o mundo e o para-si, pois esta totalidade de seres existe para ser transcendida, para ser negada, ela deve ser, por isso, tomada como meio "hostil" que deve ser vencido, meio

1 Devemos ressaltar que esta ipseidade é o "segundo aspecto essencial da pessoa"; o primeiro foi determinado quando a consciência expulsou o ego de sua interioridade e o transformou em um em-si, a partir do momento em que ela foi definida como "presença a si". 
no qual surgem as resistências. Neste momento o para-si não se reconhece mais como pertencente a esta totalidade mas como o seu polo oposto, como a figura que surge neste fundo indiferenciado de seres. Notamos a "dissensão" na totalidade que é o mundo, representada pelo desejo de ser que é típico do para-si. Se o mundo surge como totalidade, é também como objetividade a ser negada que ele aparece ao para-si. É no mundo que se dá a relação entre o em-si e o para-si.

Devemos destacar, entretanto, que Sartre insiste na tese de que a síntese entre o em-si e o para-si, ainda que seja impossível, "é sempre indicada" (SARTRE, 1997, p. 759). É o hiato mantido entre os dois modos de ser que torna impossível a síntese, e este hiato impede que ocorra a dissolução de um no outro, o que acarretaria a redução da passividade à atividade ou vice-versa, ou seja, a extinção da relação contraditória entre os dois modos fundamentais de ser. Mas é também a necessidade essencial do para-si de ser o seu si que a mantém sempre "indicada". Não precisamos reafirmar que a consequência desta ambiguidade é a "repetição sisífica" do fracasso do para-si. Passamos a notar, então, que a totalidade em-si-para-si é sempre posta mas sempre desagregada. Posta como ideal e destruída pela separação identificada entre os lados da pretendida síntese. Notamos que a cisão antes presente no ser da consciência agora é identificada também neste ser que surgiria como a síntese entre os dois modos de ser. O ser em-si-para-si existe somente como o ideal do parasi. Este ser projetado e negado, ao mesmo tempo, surge como a ambiguidade que caracteriza o ser ideal do para-si. Ambiguidade que está na raiz do ser do valor. Este ser que é pretendido, mas que é denegado, este ser ideal nada mais é do que a totalidade destotalizada, identificada agora, no ser, não só no parasi ou na relação entre o para-si com outrem.

Se podemos estabelecer a relação entre a consciência e o em-si, esta somente se dá como captação que o primeiro termo faz do segundo. O ser "é aquele que é captado" (SARTRE, 1997, p. 761). Isto significa que "[...] seu ser não coincide de modo algum com seu ser-captado" (SARTRE, 1997, p. 761). Se admitimos que a consciência estabelece uma relação com o em-si, a questão da totalidade pode ter um lugar, pois, de alguma forma, sou "[...] ao mesmo tempo consciência do ser e consciência (de) mim" (SARTRE, 1997, p. 761). O que Sartre estabelece, entretanto, é que o modo como ela pode ser explicitada não pertence ao setor da ontologia. Ao menos aquela que ele formula, pois somente temos dois modos concretos de ser, o em-si e a consciência; o terceiro funciona como o ideal da consciência, o em-si-para-si. O estabelecimento da realidade desta idealidade não pode ser aventado pela ontologia sartreana. 
O que significa que a resposta ao modo como a totalidade pode ser dada somente encontra lugar na metafísica. Neste sentido, a ontologia sartreana encontra o seu limite. Além disto, Sartre avalia que somente após a solução desta questão de fundo é que a metafísica poderá abordar o problema “[...] concernente à ação" (SARTRE, 1997, p. 762). Este problema pertence ao setor da metafísica, segundo Sartre, porque qualquer ato humano estabelece, de algum modo, a relação da consciência com o ser. Isto requer que a elucidação da "[ [...] eficácia transcendente da consciência" (SARTRE, 1997, p. 762) tenha seu lugar de fato. Por outro lado, ela exige que a correlação exterioridade-interioridade seja superada, pois toda ação é "[...] um projeto de origem imanente, que determina uma modificação no ser do transcendente" (SARTRE, 1997, p. 762), porque a ação somente pode ser considerada no contraponto entre o real e o possível, entre o ser e o não-ser. Se a consciência é o fator de instauração de uma ação possível no mundo, ela também é a afirmação de uma idealidade correspondente, posto que sempre visa à supressão de suas carências, a ultrapassagem de sua falta essencial. Isto pode ser admitido porque o valor é "[...] a falta em relação à qual o Para-si determina a si mesmo em seu ser como falta" (SARTRE, 1997, p. 763). Se assim é, encontramos na relação entre a consciência e o ser o sentido do valor. Com o valor notamos que a ação humana visa a superar a falta, que nada mais é do que o preenchimento da lacuna, do hiato encontrado em seu próprio ser. É na identificação deste valor ideal das ações humanas que Sartre centraliza o surgimento da tarefa da metafísica. Somente ela poderá determinar o sentido específico desta idealidade.

Neste momento encontramos o segundo aspecto que desejamos ressaltar. Se não devemos somente visar ao aspecto material da ação, mas o seu lado "ideal", isto exige que o "espírito de seriedade" seja negado. Tal constatação se impõe porque, para Sartre, esta postura, além de eliminar a subjetividade da transcendência dos valores, transfere "[...] o caráter de 'desejável' da estrutura ontológica das coisas para sua simples constituição material" (SARTRE, 1997, p. 763). O que está por trás desta renúncia ao "espírito de seriedade" é a necessidade de manutenção dos "valores simbólicos" (SARTRE, 1997, p. 763) do mundo. Em outros termos, que o mundo no qual o homem habita não seja simplesmente o da materialidade ou do em-si. Em suma, que se tente renunciar ao ato de má-fé, ato que procura reduzir o campo da possibilidade ao da pura necessidade, que visa, no fundo, a excluir a liberdade das ações humanas e a angústia que as caracteriza. Se o "espírito de seriedade" procura obscurecer "[...] todos os seus objetivos para livrar-se da angústia" (SARTRE, 1997, p. 764), a metafísica deve avaliar se este ato é desejável. Se 
o mundo é uma "exigência muda", o ato que se limita a esta exigência também acaba por ser uma "obediência" a esta determinação. Agir de má-fé significa negar a idealidade, aniquilar o valor. No plano estrito da materialidade todos os fins são equivalentes. Somente a ação humana que visa a um ideal transcendente pode "valorar" o mundo. Agir de má-fé é tentar aniquilar a transcendência dos atos humanos.

É neste contexto que Sartre pergunta: quem será o "agente moral"? Aquele que age de má-fé ou aquele que enfrenta a liberdade e a angústia? É por isso que o problema do valor põe em discussão o sentido que deve ter a liberdade para a postura metafísica. Será que a liberdade passa a ser o fundamento do valor? Ou então, mantendo a transcendência, coloca-se o valor em outra instância? Estas questões apontam para a função que a metafísica poderia desempenhar, principalmente a de responder aos problemas que a ontologia não tem condições de fazê-lo. Isto nos leva a crer que uma solução possível para o problema da síntese em-si-para-si não encontra lugar nos dados postos somente pela ontologia sartreana. Vislumbramos aqui a relevância dos estudos empreendidos pela Crítica da razão dialética.

\section{Conclusão}

Podemos agora finalizar e desejamos fazê-lo estabelecendo que o valor foi considerado como o modo de ser originário da totalidade, mas também como projeto fracassado que se desintegrou no momento em que foi apresentado como fundamento. Ele é o ser para o qual a realidade humana caminha sem cessar. Um ser que é, de modo ambíguo, afirmado e recusado. Se esta tese é válida, acreditamos que a análise que empreendemos da ontologia sartreana torna possível compreendê-la como uma tentativa de esclarecer o modo como a consciência pode tomar o ser como o seu objeto de "atenção". Como, de modo mais amplo, a realidade humana pode modificar a "[...] sua relação com este ser" (SARTRE, 1997, p. 67) e também como ela pode, neste mesmo ato, visar ao ser em sua totalidade projetando um modo de "ser todo".

\section{Referências}

HOWELLS, C. The Cambridge companion to Sartre. Cambridge, UK: Cambridge University Press, 1992. 
NATANSON, M. A critique of Jean-Paul Sartre's ontology. Nebraska: University of Nebraska, 1951.

PRESSEAULT, J. L'Être-pour-autrui dans la philosophie de Jean-Paul Sartre. Bruxelas: Desclée de Brouwer, 1970.

ROUGER, F. Le monde et le moi. Paris: Méridiens Klincksieck, 1986.

SARTRE. J-P. O ser e o nada. Tradução de Paulo Perdigão. Petrópolis: Vozes, 1997. SARTRE. J-P. Crítica da razão dialética. Tradução de Guilherme João de Freitas Teixeira. Rio de Janeiro: DP\&A, 2002.

Recebido: 20/07/2010

Received: 07/20/2010

Aprovado: 02/09/2010

Approved: 09/02/2010 